\title{
The Season for Peace: Reconciliation in a Despotic Species (Lemur catta)
}

\author{
Elisabetta Palagi ${ }^{1,2 *}$, Ivan Norscia $^{1}$ \\ 1 Natural History Museum, University of Pisa, Calci, Pisa, Italy, 2 Institute of Cognitive Sciences and \\ Technologies, Unit of Cognitive Primatology \& Primate Center, CNR, Rome, Italy \\ * elisabetta.palagi@ @unipi.it
}

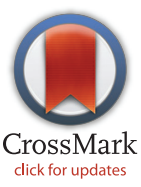

\section{G OPEnACCESS}

Citation: Palagi E, Norscia I (2015) The Season for Peace: Reconciliation in a Despotic Species (Lemur catta). PLoS ONE 10(11): e0142150. doi:10.1371/ journal.pone.0142150

Editor: Karen E. Samonds, Northern Illinois University, UNITED STATES

Received: February 9, 2015

Accepted: October 19, 2015

Published: November 16, 2015

Copyright: ๑ 2015 Palagi, Norscia. This is an open access article distributed under the terms of the Creative Commons Attribution License, which permits unrestricted use, distribution, and reproduction in any medium, provided the original author and source are credited.

Data Availability Statement: All relevant data are within the paper and its Supporting Information files.

Funding: The authors only received reimbursement for travel and accommodation fees from Giardino Zoologico di Pistoia, Parco Zoo Falconara (Falconara, Italy), and Parco Zoo Punta Verde (Lignano Sabbiadoro, Italy). No official grant or funding (with grant numbers) was obtained and no salary was received for the investigation, which was carried out with the authors' own funds.

Competing Interests: The authors have declared that no competing interests exist.

\section{Abstract}

However despotic a social group may be, managing conflicts of interest is crucial to preserve group living benefits, mainly based on cooperation. In despotic groups, post-conflict management via reconciliation (the first post-conflict reunion between former opponents) can occur, even if conciliatory rates are considerably different. Lemur catta is defined as a despotic species because groups are characterized by a strict linear hierarchy maintained by the adult females (the dominant sex) mainly via aggression. Reconciliation was reported in one out of four captive groups of $L$. catta. Here we investigate which variables influence the occurrence of reconciliation in these despotic groups. We analyzed 2339 Post Conflict (PC)-Matched Control (MC) observation pairs, collected on eight groups (five in the Berenty forest, Madagascar; three hosted at the Pistoia Zoo, Italy). Since L. catta is characterized by steep female dominance but shows female-female coalitionary support, we expected to confirm the presence of reconciliation in the study species. Consistently, we found reconciliation in one captive group and two wild groups, thus providing the first evidence of the presence of this phenomenon in wild $L$. catta. Moreover, because this species is a seasonal breeder (with mating occurring once a year), we expected seasonal fluctuations in reconciliation levels. Via a GLMM analysis using data from all wild groups and on a captive group followed for more than one year, we found that season (but not rank; individuals' identity, sex, and age; or group identity) significantly affected individual reconciliation rates, and such rates were lowest during the mating period. Thus, reconciliation can be present in groups in which dominants strongly influence and limit social relationships (steep dominance hierarchy) except when the advantages of intra-group cooperation are overcome by competition, as occurs in seasonal breeders when reproduction is at stake. We conclude that in despotic social groups in which coalitions are observed, the right question is not if but when reconciliation can be present.

\section{Introduction}

The management of conflicts of interest is crucial to preserve group living benefits, even in despotic societies. In these kinds of societies, to preserve social integrity, violence is minimized via 
the strict control exerted by dominants over other individuals ("negative peace", sensu Galtung [1]). Yet, in humans and other social mammals, dominant individuals or subgroups may need the support of others to obtain resources and maintain the status quo [2-7]. Consequently, strategies of mutual help other than competition for dominance and resources must be enabled, such as cooperative breeding, hunting, and coalitionary support during betweengroup conflicts [8-11].

Reconciliation or peace-making, defined as the first affinitive contact between former opponents occurring within few minutes after the conflict, is one of the main mechanisms to manage conflicts [12]. The phenomenon is present in social animals, including a bird species (e.g. ravens, Corvus corax [13]), various non primate mammals (e.g. domestic goats, Capra hircus [14]; dolphins, Tursiups troncatus [15]; domestic dogs, Canis lupus familiaris [16]; horses, Equus caballus [17]; red-necked wallabies, Macropus rufogriseus [18]), and human and non human primates (Homo sapiens [19]; chimpanzees, Pan troglodytes [20], [21]; bonobos, Pan paniscus [22]; Gorilla beringei and Gorilla gorilla [23-25]; wild macaques, Macaca spp. [26, 27]; captive guereza, Colobus guereza [28]; captive patas monkeys, Erythrocebus patas [29]; captive squirrel monkeys, Saimiri sciureus [30]; captive white-faced capuchins, Cebus capucinus [31]).

By restoring the relationship between former opponents [32-39], reducing the probability of further fights [23], [33], [34], [40-45] and/or reducing anxiety in the victim [21], [46-50], reconciliation is crucial to preserving social unity from the disruption caused by uncontrolled conflict spreading in the group. Therefore, reconciliation is expected to be present any time that it is valuable for the group members (including dominants) to preserve the alliances that facilitate group survival, thus preserving the benefits of group living [51].

Consistently, reconciliation has been found also in species with a despotic dominance style [5; 52-55]. According to the definition of Flack and de Waal [52], in despotic groups dominance dyadic asymmetries remains quite stable over time because they reinforced through severe aggression. Instead, in tolerant groups dyadic asymmetries can exist but many relationships are unresolved. Examples of animals living in despotic groups and that are able to reconcile include spotted hyenas (Crocuta crocuta [53]), wolves (Canis lupus lupus [5]), Japanese macaques (Macaca fuscata [54]), and wild chacma baboons (Papio ursinus: Cheney, Seyfarth \& Silk [55]). Similar to these species, Lemur catta can be defined as despotic because groups are characterised by a linear and steep hierarchy with clear-cut dominance relationships [56]. Females are dominant and their dominance is maintained also through severe aggression by dominants over subordinates [56-63]. In this species, the presence of reconciliation was found in one out of four captive troops in which post-conflict management was studied [64],[65].

The linkage between reconciliation and the level of authoritativeness (or despotism) has been qualitatively examined in humans, with friendly peacemaking being favored by minimal authority (power exercised over others; [66]). The linkage between reconciliation and dominance style has been also quantitatively assessed in tolerant to despotic macaque species ([52], [67]), with tolerant species (e.g. Tonkean macaques, Macaca tonkeana [37],[68], [69-71]) showing higher reconciliation levels than despotic species (Japanese macaques, Macaca fuscata [54]). The same linkage has been hypothesized in strepsirrhine primates [64], which can also show more or less mild and flexible dominance hierarchies [56]. In this primate taxon, reconciliation was indeed found in species with more relaxed (i.e. less steep or transitive) dominance relationships (captive Eulemur wild Eulemur rufusxcollaris [45]) rufus [64], [72]; wild Propithecus verreauxi [73]) but not in captive Eulemur macaco showing strong female dominance [72].

In the present study, we investigate the factors that can explain the occurrence of reconciliation (or lack thereof) in different captive and wild groups of $L$. catta and make inferences about the conditions that favor the presence of reconciliation in despotic groups. As a primate species 
belonging to the group (strepsirrhines) that diverged from the common ancestor some 60 million years ago [74], L. catta also offers the possibility to make inferences about the biological roots of peace-making dynamics found in humans and all other primates. For this investigation, we analyzed the data collected on the focal species both in the wild and in captivity across more than a decade to verify the following predictions:

\section{Prediction 1}

Similar to wolves and hyenas [5], [75], [76] L. catta is characterized by rigid hierarchy and high competition levels [57-63], [77-79]. Analogous to ring-tailed lemur troops, packs (in the case of wolves; [80]) and clans (in the case of hyenas [81], [82]) strictly defend their territories by directing severe aggression towards potential immigrants. Finally, although in a more limited form compared to canids and hyenids, L. catta females (the dominant sex in this species) are able to form coalitions, especially against other females, to preserve their dominance status or to gain the possibility to use a territory [10]. These traits led us to predict that, as in other despotic but cooperative species [58], reconciliation may be present in L. catta not only in captivity but also in the wild.

\section{Prediction 2}

In the animals breeding once or twice in the year, seasonality strongly affects social behaviour and competition levels [83]. Majolo \& Koyama [84] found that in the population of despotic Macaca fuscata from Yakushima Island reconciliation levels changed seasonally. As most lemur species, $L$. catta lives and has evolved in a highly seasonal environment [61], [85,86] and is a seasonal breeder [58]. In fact, females are receptive once a year [87-89] and the mating period (from three weeks to two months depending on the site and the definition; see also: [57], [58], [90], [91]) is characterised by high competition and low affiliation levels. During the mating period, competition within and between sexes is extremely high and affiliation levels are low [58], [77], [92], [91]. Therefore, we expected that in L. catta seasonality would particularly affect reconciliation levels.

\section{Methods}

\section{Ethics statement}

Since the study was purely observational the Animal Care and Use board (University of Pisa) waived the need for a permit. The study was conducted with no manipulation of animals. The study was carried out in the private Reserve of Berenty (South Madagascar) and at the Pistoia Zoo (Pistoia, Italy). De Heaulme and family, owners of Berenty and Mr Cavicchio, owner and director of the Pistoia Zoo, permitted us to observe animals.

\section{Study species}

Lemur catta (ring-tailed lemur) is a cathemeral species characterized by seasonal fluctuations in olfactory behavior, group dispersal, tolerance level, and reproduction [58], [78], [79], [9397]. Lemur catta has a steep, consistent, highly transitive and cohesive hierarchy (sensu Norscia and Palagi [56]), with females dominant over males [58], [59], [78], [98-99]). Male hierarchy is unstable, and at times, non-transitive, and both female-female and male-male dominance hierarchies are fluid and can change over time [100-102].

The mating season overlaps among the different groups of a population and can last from three weeks to two months (depending on the site, the year, the definition of mating period; [57], [58], [90], [91], [103]. However, the onset of the mating period varies between groups, 
and the whole mating season for the lemur population spans up to four months [57],[103]. Females experience an annual estrus of a few hours to days, and receptivity lasts $10-24 \mathrm{~h}$ after which the estrus period ends [58], [87]-[89], [59]. A second or third belated estrus is possible [58], [78], [79]). Lemur catta females have a visible estrus, which may be asynchronous with other females in their group [104]. The mating period starts about one month before copulations, when female perineal area starts to enlargen and the center of the genitalia becomes larger and pinker: this period of swelling anticipates estrus [58], [87]. Generally, receptivity coincides with the last day of maximal pink coloration of vaginal labia ([87], [103].

\section{Study location and subjects}

Berenty (Madagascar). We conducted this research on wild lemurs in the gallery forest of Berenty, a reserve on the Mandrare River in Southern Madagascar (for an extensive description of the forest, see [105]). Data collection was conducted in the northern part of the forest called Ankoba (S 24.998; E 46.298), a 40-ha secondary forest 50- to 60-years-old, with canopy at 10$15 \mathrm{~m}$ (except for few emergent acacias to more than $20 \mathrm{~m}$ ) and high lemur density [105]. Observations were carried out in the periods November 2006-February 2007, April-July 2008, and March-April 2011 on five troops of L. catta. Details on group composition and observation periods are reported in Table 1. Kin relationships among group members were unknown but groups at Berenty (and other sites) are largely female matrilines (including sibling and offspring of the alpha female [10],[59], [106], [107]. The individuals were well habituated to the presence of humans. As in previous studies, individual identification was based on sex and distinctive external features [56-58].

Pistoia Zoo (Italy). We studied three captive troops (here named A, B, and C) at the Pistoia Zoo (Italy) in the periods February-May 1999, November 2003-February 2005. Details on group composition and observation periods are reported in Table 1. The captive groups were largely composed by the alpha female and kin (siblings and offspring of the alpha female). The lemurs were housed in an outside grassy enclosure $\left(98 \mathrm{~m}^{2}\right)$. In 1999, groups A and B were kept in two separated indoor halls on the coldest days of the year (A: $10 \mathrm{~m}^{2}$ indoor facility; B: $20 \mathrm{~m}^{2}$ indoor facility). Large glass windows in the two indoor facilities allowed the lemurs to follow the natural day-light 24-h cycle. Each group utilized the outside enclosure for 4-6 h per day, separately. In 2003-2005, another group $\left(\mathrm{C}_{c}\right)$ was hosted at the zoo and could use the indoor facility previously used by the other groups (not present anymore). The observations took place outdoors and lasted from the end of October 2003 to February 2015. As in the wild and in previous studies at Pistoia Zoo, individual identification in captivity was based on sex and distinctive external features [57] [65], [73], [74].

Table 1. Composition of wild and captive groups, observation $\mathbf{n}$ periods and study sites.

\begin{tabular}{|c|c|c|c|c|c|c|c|}
\hline Group & Observation months & Period & Males $_{\text {adult }}$ & Females adult & Males $_{\text {juvenile }}$ & Females $_{\text {juvenile }}$ & Study site \\
\hline & & & & & & & WILD \\
\hline$A_{w}$ & $\mathrm{Nov}_{2006}-\mathrm{Feb}_{2007}$ & Lactation & 4 & 4 & 1 & 0 & Berenty \\
\hline $\mathrm{B}_{\mathrm{w}}$ & $\mathrm{Nov}_{2006}-\mathrm{Feb}_{2007}$ & Lactation & 4 & 6 & 2 & 1 & Berenty \\
\hline $\mathrm{C}_{\mathrm{w}}$ & May-Jul 2008 & Pregnancy & 3 & 6 & 1 & 2 & Berenty \\
\hline$D_{w}$ & Apr-Jun $_{2008}$ & Mating & 6 & 8 & 1 & 3 & Berenty \\
\hline \multirow[t]{2}{*}{$E_{w}$} & Mar-Apr 2011 & Premating & 5 & 5 & 5 & 2 & Berenty \\
\hline & & & & & & & CAPTIVITY \\
\hline$A_{c}$ & Feb-Mar $_{1999}$ & Pregnancy & 2 & 3 & 0 & 0 & Pistoia \\
\hline $\mathrm{B}_{\mathrm{c}}$ & Apr-May 1999 & Lactation & 2 & 4 & 2 & 0 & Pistoia \\
\hline $\mathrm{C}_{\mathrm{c}}$ & $\mathrm{Nov}_{2003}-\mathrm{Feb}_{2005}$ & Premating, Mating, Lactation, Pregnancy & 4 & 4 & 0 & 2 & Pistoia \\
\hline
\end{tabular}

doi:10.1371/journal.pone.0142150.t001 


\section{Data collection}

Systematic data collection was preceded by a training period that lasted until the data collected by the two observers (on aggression and affiliation behavioral patterns) matched in $95 \%$ of cases [108]. The excellent visibility condition of the Berenty forest allowed us to apply the same protocol to the wild as was used in captivity. For each agonistic encounter we recorded: (1) identity of the two opponents; (2) aggressive behavioral patterns (mainly chase, bite, grab, jump); and (3) submissive/frightened patterns (flee and vocalization). The agonistic interaction was labeled as "decided" when one of the two opponents gave up the fight (by retreating, fleeing or running away) and the winner could be therefore determined with certainty. For a comprehensive ethogram see [109].

After the last aggressive pattern of any given agonistic event, we followed the loser of the interaction (as the focal individual) for a $10 \mathrm{~min}$ post-conflict period (PC). Matched control observations (10 minute long MCs) took place during the next possible day at the same time, context (feeding, resting or travelling) and physiological season (lactation, pre-mating, mating, and pregnancy; see details below) as the original PC. MC data were collected only if all these conditions were met. The MC was conducted on the same focal animal, in the absence of agonistic interactions during the $10 \mathrm{~min}$ before the beginning of the $\mathrm{MC}$ and when the opponents had the opportunity to interact, within a distance of $10 \mathrm{~m}$ maximum [110], [111]).

We considered four groups of affinitive behaviors to identify the first conciliatory contact: body contact (body-to-body contact excluding tails, huddle); greeting (naso-nasal, face grooming); grooming (unidirectional, reciprocal or mutual); olfactory contact (sniffing body, sniffing genitals, and skin licking) [109]). Proximity was not considered because it does not necessarily indicate affiliation. We collected a total of 2339 PC-MC (1461 in captivity and 878 in the wild). For both PCs and MCs we recorded: (1) starting time; (2) type of first affinitive interaction; (3) time of first affinitive contact; (4) partner identity.

\section{Operational definitions and data analysis}

Reconciliation analysis was carried out at the individual level, taking the recipient of the aggression as the individual of reference. For each animal we determined the number of attracted, dispersed and neutral pairs over all PC-MC pairs. In attracted pairs, affinitive contacts occurred earlier in the PC than in the MC (or they did not occur at all in the MC), whereas in dispersed pairs the affinitive contacts occurred earlier in the MC than in the PC (or they did not occur at all in the PC). In neutral pairs, affinitive contacts occurred during the same minute in the PC and the MC, or no contact occurred in either the PC or the MC [110].

Due to the small sample size and/or deviation from normality (Exact Kolmogorov-Smirnov, $\mathrm{p}<0.05$ ) we used the Exact Wilcoxon signed-ranks test [112], [113] to compare attracted versus dispersed pairs. Attracted and dispersed pairs were measured at the individual level, thus ensuring the independency of data points. The pair-wise comparison between attracted and dispersed pairs allows checking whether reconciliation is present (if the number of attracted pairs is significantly higher than the number of dispersed pairs) or not.

In addition to determining whether reconciliation was present or not, we assessed the individual rates of conciliatory tendencies of individuals. The measure of corrected conciliatory tendency (CCT; [114]) allows evaluating the level of individual reconciliation by considering the attracted minus dispersed pairs divided by the total number of PC-MC pairs. Individual CCTs were used to determine the mean CCT in wild and captive conditions.

To assess the effect of the different factors on individual CCTs (scalar, dependent variable), we ran two sets of General Linear Mixed Model (GLMM). The first GLMM was performed on all the study groups (Table 1). As fixed factors, we considered sex (binomial: male/female), age 
(binomial: juvenile/adult), rank position (scalar), season (multinomial: 1-4), individuals (nominal), and groups (nominal). Due to the inter-independence of sex and age, and sex and rank (because females outrank males and adults outrank subadults), these three factors were entered as two combined variables (sex* rank and age* rank). In order to attempt to remove possible confounding variables, the second GLMM was performed only on groups $\mathrm{C}_{\mathrm{c}}$ for which data collection had covered all seasons (Table 1). We considered the same fixed factors included in the first GLMM except for group ID.

Since CCT distribution was normal in both cases (Kolmogorov-Smirnov, $\mathrm{p}=\mathrm{n} . \mathrm{s}$.), an identity link function was used. We tested models for each combination involving the variables of interest, spanning from the null model (only intercept) to the model including all the fixed factors (full model). To select the best model, we used the Akaike's Corrected Information Criterion (AICc), a measure for comparing mixed models based on the -2 (Restricted) log likelihood. The AICc corrects the Akaike's Information Criterion (AIC) for small sample sizes. As the sample size increases, the AICc converges to AIC. The model with a lower value of AICc was considered to be the best model. To avoid the increase of type II errors, factors were excluded from a model only if this improved the model fit by $>2$ AICc units [115]. The value of degrees of freedom is given by the effective sample size $(\mathrm{N})$ minus the rank design matrix of fixed effects (X). The denominator degree of freedom is estimated by SPSS via Satterthwaite's approximation.

We used all dyadic decided agonistic interactions to prepare a winner/loser socio-matrix and carry out hierarchical rank order analysis, by using MatMan 1.0 based on I\&SI rankings (Noldus Information Technology, Wageningen, Netherlands; [116]). To assign the age class to each animal, the individuals were distinguished between adults (regularly performing genital marking, informing an age $>18$ months) and juveniles (not performing genital marking) [117].

Four seasons were recognized: lactation (1), pre-mating (2), mating (3), pregnancy (4) (The numbers correspond to how the seasons have been entered in the GLMM model). For the captive groups (in the northern hemisphere) the different seasons were: lactating season (group $B_{c}$ : April-May 1999; group $C_{c}$ : April-August 2004); pre-mating (group $C_{c}$ : September-October 2004), mating (group $C_{c}$ : November-December 2003; November-December 2004), pregnancy (group $A_{c}$ : February-March 1999; group $C_{c}$ : January-March 2004; January-February 2005). Individual CCTs for group $\mathrm{C}_{\mathrm{c}}$ (observed for more than one season) were calculated using the PC-MC collected for each season. In the wild the mating period varied depending on the group (refer to Table 1 for the groups): pre-mating (group $\mathrm{E}_{\mathrm{w}}$ : March-April: 2011), mating (group $\mathrm{D}_{\mathrm{w}}$ : April-May-beginning of June 2008), pregnancy (group $\mathrm{C}_{\mathrm{w}}$ : May-July 2008), and lactating season (groups $A_{w}$ and $B_{w}$ : November-February 2006). The mating period began when at least one female of the group started showing genital swelling from about $1.5-3 \mathrm{~cm}$ in length and developing a pink center [57], [58]. In a group, the pregnancy was considered as starting after the last copulation day (confirmed ex-post by births) whereas lactation started when a female in the group gave birth. Overall two mating periods were available in captivity and one in the wild.

\section{Results}

A previous study [65] showed that reconciliation was present in captive group $A_{c}$ but not in group $\mathrm{B}_{\mathrm{c}}$ (Table 1) so those analyses are not reported here. The overall CCT calculated here for the first time for all groups was $10.25 \% \pm 2.24$ (Mean \pm SE). In the wild the CCT was $10.99 \%$ \pm 2.44 and in captivity $9.62 \% \pm 3.60$ (Mean \pm SE). Mean CCT\% ( \pm SE) for each group are reported in Table 2. 
Table 2. Mean Corrected Conciliatory Tendency (CCT \%) \pm Standard Error (SE) for each study group.

\begin{tabular}{ll}
\hline Group & CCT\%: Mean \pm SE \\
\hline$A_{w}$ & $19.55 \pm 7.52$ \\
$B_{w}$ & $18.62 \pm 8.51$ \\
$C_{w}$ & $14.63 \pm 6.96$ \\
$D_{w}$ & $5.74 \pm 2.72$ \\
$E_{w}$ & $3.69 \pm 2.20$ \\
$A_{c}$ & $43.17 \pm 19.24$ \\
$B_{c}$ & $-14.83 \pm 4.23$ \\
$C_{c}$ & $9.47 \pm 6.73$ \\
\hline
\end{tabular}

doi:10.1371/journal.pone.0142150.t002

For captive group C (Table 1) we found a significant difference between the number of attracted pairs (in which affinitive contacts occurred earlier in the PC than in the MC or they did not occur at all in the $\mathrm{MC}$ ) and the number of dispersed pairs (in which affinitive contacts occurred earlier in the MC than in the PC or they did not occur at all in the PC; attracted $>$ dispersed pairs: $\mathrm{T}=5, \mathrm{~N}=10$, ties $=1, \mathrm{p}=0.004$; Fig 1). In the wild, reconciliation was present in two groups out of five (groups $\mathrm{C}_{\mathrm{w}}$ and $\mathrm{E}_{\mathrm{w}}$ ). In fact, we found a significant difference between attracted and dispersed pairs (attracted $>$ dispersed) for group $\mathrm{C}_{\mathrm{w}}(\mathrm{T}=0, \mathrm{~N}=12$, ties $=6, \mathrm{p}=0.031 ;$ Fig $2 \mathrm{~A})$ and group $\mathrm{E}_{\mathrm{w}}(\mathrm{T}=2.50, \mathrm{~N}=15$, ties $=6, \mathrm{p}=0.020 ;$ Fig $2 \mathrm{~B})$. No significant difference between attracted and dispersed pairs was found for group $A_{w}(T=0, N=8$, ties $=4, \mathrm{p}=0.125)$, group $\mathrm{B}_{\mathrm{w}}(\mathrm{T}=12, \mathrm{~N}=11$, ties $=2, \mathrm{p}=0.254)$ and group $\mathrm{D}_{\mathrm{w}}(\mathrm{T}=19.50$, $\mathrm{N}=18$, ties $=7, \mathrm{p}=0.254$ ).

For both captive and wild settings, the aggression distribution according to the different sex class combination is reported in Table 3 and shows that aggression levels of females toward males and between males were maximum during the mating season. During pregnancy and lactation the majority of conflicts involved females.

Of all the GLMM models tested on all groups (AICc range $=393.675-1107.725$ ) the best one was the full model (Intercept: $\mathrm{F}=1.104, \mathrm{df} 1=77, \mathrm{df} 2=38, \mathrm{p}=0.376$ ), including the combination of individual features (sex*rank: $\mathrm{F}=1.448, \mathrm{df} 1=1, \mathrm{df} 2=38, \mathrm{p}=0.236$; age ${ }^{*}$ rank: $\mathrm{F}=0.849, \mathrm{df} 1=1, \mathrm{df} 2=38, \mathrm{p}=0.363)$, the group identification $(\mathrm{F}=1.779, \mathrm{df} 1=1, \mathrm{df} 2=38$, $\mathrm{p}=0.190)$, individual identity $(\mathrm{F}=0.698, \mathrm{df} 1=64, \mathrm{df} 2=38, \mathrm{p}=0.899)$, and the season (lactation, pre-mating, mating, and pregnancy; $F=5.282, \mathrm{df1}=3, \mathrm{df} 2=40, \mathrm{p}=0.004)$. Fig 3 shows the model output for the best model. Even if part of variability is influenced by individual CCT levels, only the season had a significant effect on the distribution of CCTs, lowest during the mating season (Figs 3 and 4).

Of all the GLMM models tested for group $C_{c}($ AICc range $=393.675-534.649)$, the best one was the full model (Intercept: $\mathrm{F}=3.103$, df $1=15, \mathrm{df} 2=38, \mathrm{p}=0.002$ ), including the combination of individual features (sex*rank: $\mathrm{F}=1.448, \mathrm{df} 1=1, \mathrm{df} 2=38, \mathrm{p}=0.236$; age ${ }^{*}$ rank: $\mathrm{F}=0.849, \mathrm{df} 1=1, \mathrm{df} 2=38, \mathrm{p}=0.363)$, individual identity $(\mathrm{F}=1.805, \mathrm{df} 1=9, \mathrm{df} 2=38$, $\mathrm{p}=0.099$ ), and the season (lactation, pre-mating, mating, and pregnancy; $\mathrm{F}=3.844$, $\mathrm{df} 1=3$, $\mathrm{df} 2=38, \mathrm{p}=0.017$ ). Fig 5 shows the output for the best model. Again, two individuals accounted for part of the CCT variation but only the season had a significant effect on the distribution of CCTs throughout the year, with CCT values being minimum during the mating season (Figs 5 and 6$)$. Both in captivity and in the wild, males $\left(M_{\text {in }}\right)$ and females $\left(F_{\text {in }}\right)$ initiated the first affinitive contact with comparable frequencies in all seasons (captivity, range: $\mathrm{M}_{\text {in }}=$ $47,22-51.72 \% ; \mathrm{F}_{\text {in }}=48.28-52.77 \%$; wild, range: $\mathrm{M}_{\mathrm{in}}=46,88-50.00 \% ; \mathrm{F}_{\text {in }}=50,00-60,00 \%$ ). 


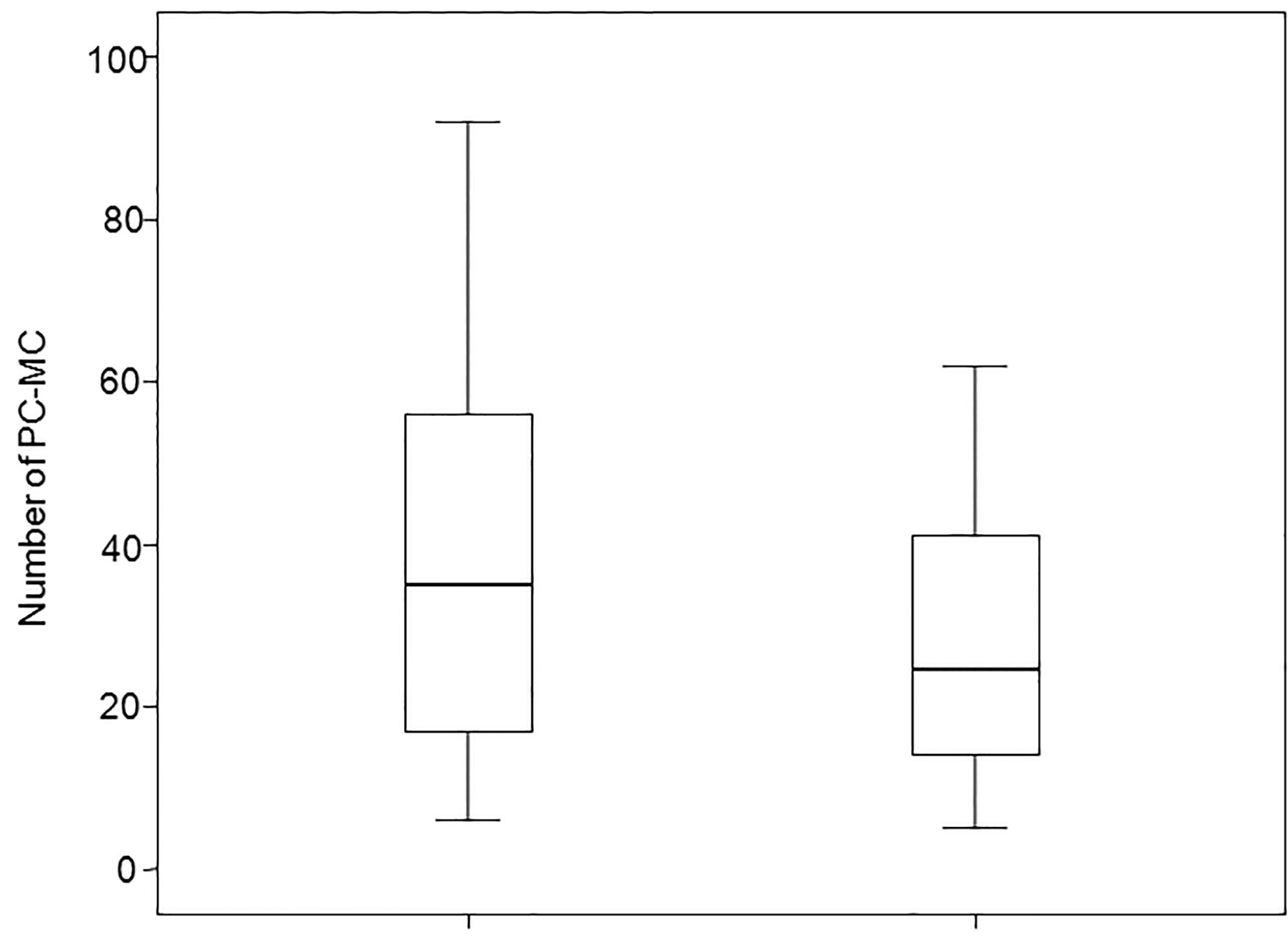

\section{Attracted pairs Dispersed pairs}

Fig 1. Box plot showing the significant difference (Exact Wilcoxon's test, $p<0.05$ ) between the number of attracted versus dispersed pairs in the Lemur catta troop $\mathrm{C}_{\mathrm{c}}$ (November 2003-February 2005), observed at the Pistoia Zoo (Italy). Solid horizontal lines indicate medians; the length of the boxes corresponds to inter-quartile range; thin horizontal lines indicate range of observed values.

doi:10.1371/journal.pone.0142150.g001

\section{Discussion}

Reconciliation was present both in the wild and in captivity (prediction 1 supported), and specifically in two out of five wild troops of $L$. catta (Fig 2) and in two captive troops (group $\mathrm{C}_{\mathrm{c}}$, present study; group $A_{c}$, [65]) (Fig 1). When considering either all the study groups or group $\mathrm{C}_{\mathrm{c}}$ only (for which longitudinal data were available), season was the only effect that significantly influenced the fluctuation in the frequency of reconciliation events (Figs 3 and 5). In particular, the conciliatory tendency was lowest during the mating season (prediction 2 supported; Figs 4 and 6).

Reconciliation was found in another despotic species with linear hierarchy, the wolf (Canis lupus; mean conciliatory tendency, $44.1 \%$ in the wild [11]; $53.3 \%$ in captivity [5]). In wolves, each group defends its own territory as a unit [118]. Yet, even if the alpha male normally 
$2 a-G r o u p C_{w}$

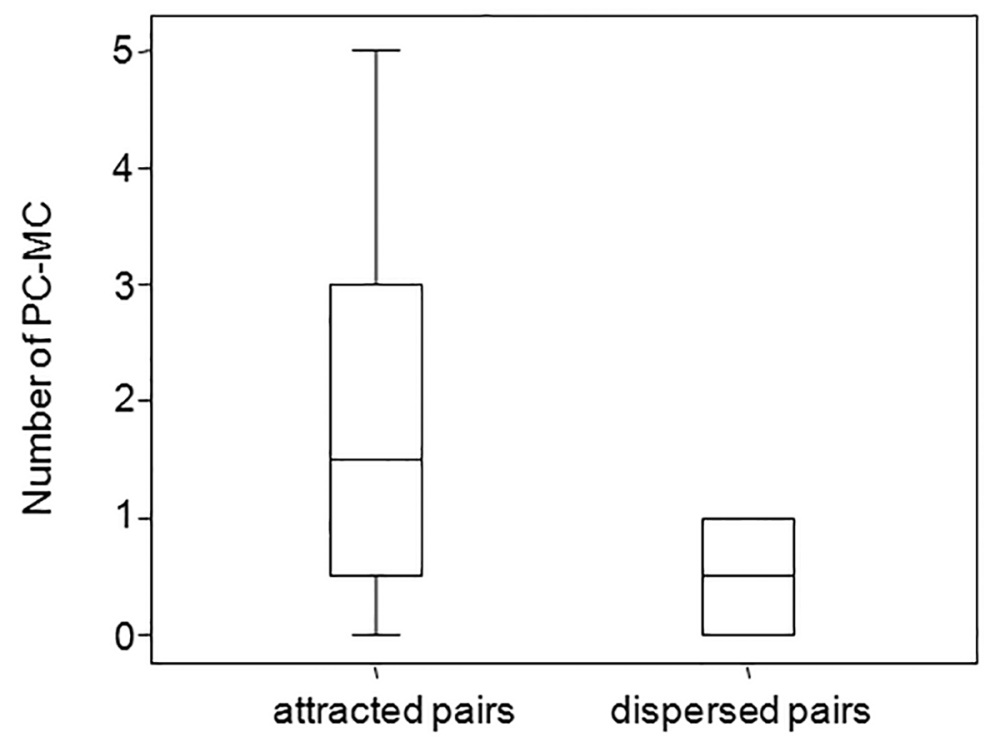

$2 b-G r o u p E_{w}$

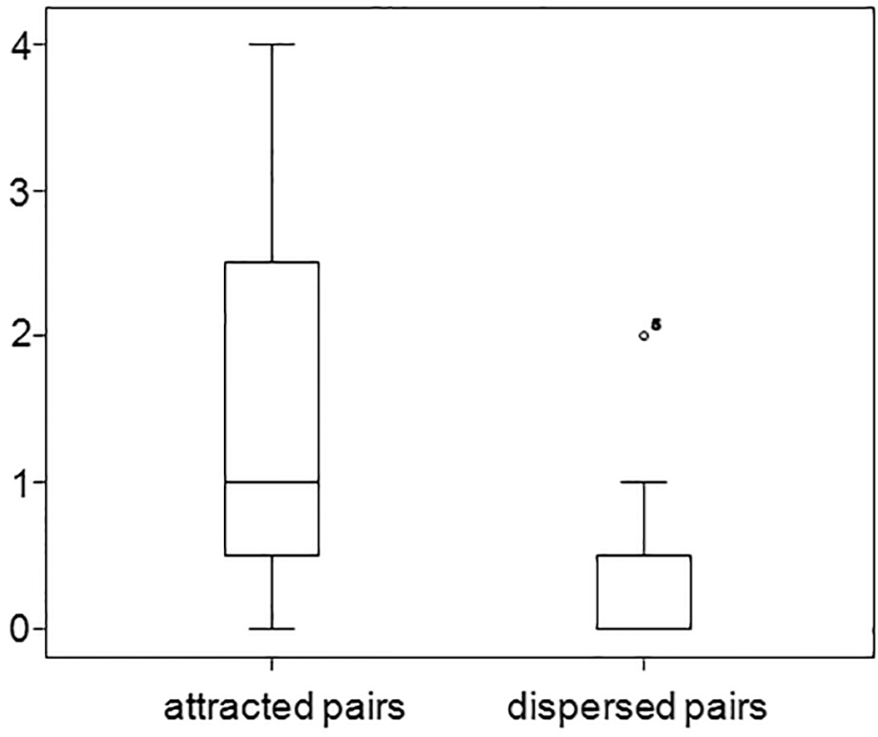

Fig 2. Box plot showing the significant difference (Exact Wilcoxon's test, $p<0.05$ ) between the number of attracted versus dispersed pairs in two wild Lemur catta troops ( $C_{w}$ : May-July 2008, Fig 2a on the left; $E_{w}$ : March-April 2011, Fig $2 b$ on the right) observed in the Berenty Forest (Madagascar). Solid horizontal lines indicate medians; the length of the boxes corresponds to inter-quartile range; thin horizontal lines indicate range of observed values.

doi:10.1371/journal.pone.0142150.g002

guides the movements of the wolf pack and initiates aggressions against intruders [118], the subordinate members can sometimes oppose their leader's actions. According to Zimen [119], no subject decides alone the carrying out of activities that are vital to the group cohesion. In short, wolves are highly despotic but also extremely cooperative. The existence of an extremely cooperative pack has presumably to do not only with hunting but also with the collective rearing of offspring and, consequently, with reproductive success [120]. Probably, in wolves the benefit of preserving the social bonds through reconciliation outweighs the cost of pack disruption, which would be detrimental for both dominants and subordinates. Thus, reconciliation can be found in despotic groups provided that they show some form of cooperation [51]. Further evidence of this assumption is the presence of reconciliation in spotted hyenas (Crocuta crocuta [53]). Hyenas are despotic but often depend on the help from other group members

Table 3. Aggression distribution (\%) according to the different sex class combinations for all seasons, in the wild (W) and in captivity (C). Sex class combinations are: $\mathrm{ff}$ (females attacking female), fm (female attacking male), $\mathrm{mf}$ (male attacking female), $\mathrm{mm}$ (male attacking male).

\begin{tabular}{ccccc}
\hline & $\mathbf{f f} \%$ & $\mathbf{f m} \%$ & $\mathbf{m f} \%$ & $\mathbf{m m} \%$ \\
\hline matingC & 11,76 & 56,62 & 3,68 & 27,94 \\
prematingC & 50 & 25 & 12,5 & 12,5 \\
pregnancyC & 43,67 & 38,61 & 5,7 & 12,03 \\
lactationC & 51,78 & 27,74 & 3,12 & 17,6 \\
matingW & 8,93 & 65,57 & 1,1 & 24,41 \\
prematingW & 28,55 & 56,62 & 0,12 & 14,7 \\
pregnancyW & 35,21 & 40,37 & 0 & 23,83 \\
lactationW & 45,64 & 41,9 & 8,23 & 4,24 \\
\hline
\end{tabular}

doi:10.1371/journal.pone.0142150.t003 


\begin{tabular}{|c|c|c|c|c|c|c|}
\hline \multirow{2}{*}{ Source } & \multirow{2}{*}{ Coefficient } & \multirow{2}{*}{$\begin{array}{c}\text { Standard } \\
\text { Error }\end{array}$} & \multirow{2}{*}{$\mathrm{t}$} & \multirow{2}{*}{$\mathrm{p}$} & \multicolumn{2}{|c|}{ Confidence interval $95 \%$} \\
\hline & & & & & Minimum & Maximum \\
\hline Intercetta & $1,126.377$ & 671.688 & 1.677 & .102 & -233.384 & $2,486.138$ \\
\hline GROUP $=A c$ & $-1,062.512$ & 717.092 & -1.482 & .147 & $-2,514.189$ & 389.166 \\
\hline GROUP $=A w$ & $-1,266.527$ & 995.417 & -1.272 & .211 & $-3,281.642$ & 748.589 \\
\hline GROUP=Bc & -861.361 & 550.575 & -1.564 & .126 & $-1,975.943$ & 253.220 \\
\hline GROUP $=B w$ & $-1,253.525$ & 873.300 & -1.435 & .159 & $-3,021.429$ & 514.379 \\
\hline GROUP $=\mathrm{Cc}$ & $-1,077.462$ & 752.796 & -1.431 & .161 & $-2,601.418$ & 446.494 \\
\hline GROUP=Cw & $-1,205.168$ & 792.394 & -1.521 & .137 & $-2,809.286$ & 398.949 \\
\hline GROUP=Dw & -569.444 & 426.956 & -1.334 & .190 & $-1,433.770$ & 294.883 \\
\hline GROUP=Ew & $0^{a}$ & & & & & \\
\hline SUBJECT $=\mathbf{2 t}$ & -455.016 & 325.959 & -1.396 & .171 & $-1,114.885$ & 204.852 \\
\hline SUBJECT=3b & $-1,165.016$ & 754.169 & -1.545 & .131 & $-2,691.750$ & 361.718 \\
\hline SUBJECT=an & -102.413 & 43.856 & -2.335 & .025 & -191.195 & -13.631 \\
\hline SUBJECT=ank & -20.528 & 44.935 & -0.457 & .650 & -111.494 & 70.439 \\
\hline SUBJECT=ba & -157.582 & 253.570 & -0.621 & .538 & -670.907 & 355.742 \\
\hline SUBJECT=bb & 232.797 & 273.000 & 0.853 & .399 & -319.863 & 785.458 \\
\hline SUBJECT=be & -86.981 & 54.190 & -1.605 & .117 & -196.683 & 22.720 \\
\hline SUBJECT=bi & 267.280 & 87.576 & 3.052 & .004 & 89.993 & 444.568 \\
\hline SUBJECT=bi1 & -605.169 & 406.839 & -1.487 & .145 & $-1,428.772$ & 218.434 \\
\hline 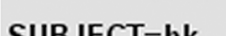 & cosin & ס & 2132 & nan & דדר גר & כתם כ \\
\hline
\end{tabular}

Fig 3. Output of the best model explaining the distribution of Corrected Conciliatory Tendencies (CCT \%, scalar target variable) for all the study groups. AICc $=430$, 295. Season: 1 = lactation; 2 = pre-mating; $3=$ mating; $4=$ pregnancy. Sex: $0=$ male; $1=$ female. Age class: $0=$ subadult; $1=$ adult. Rank

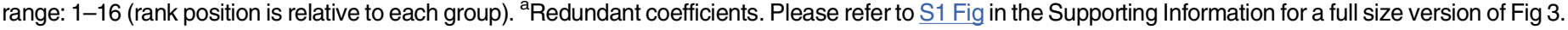

doi:10.1371/journal.pone.0142150.g003 


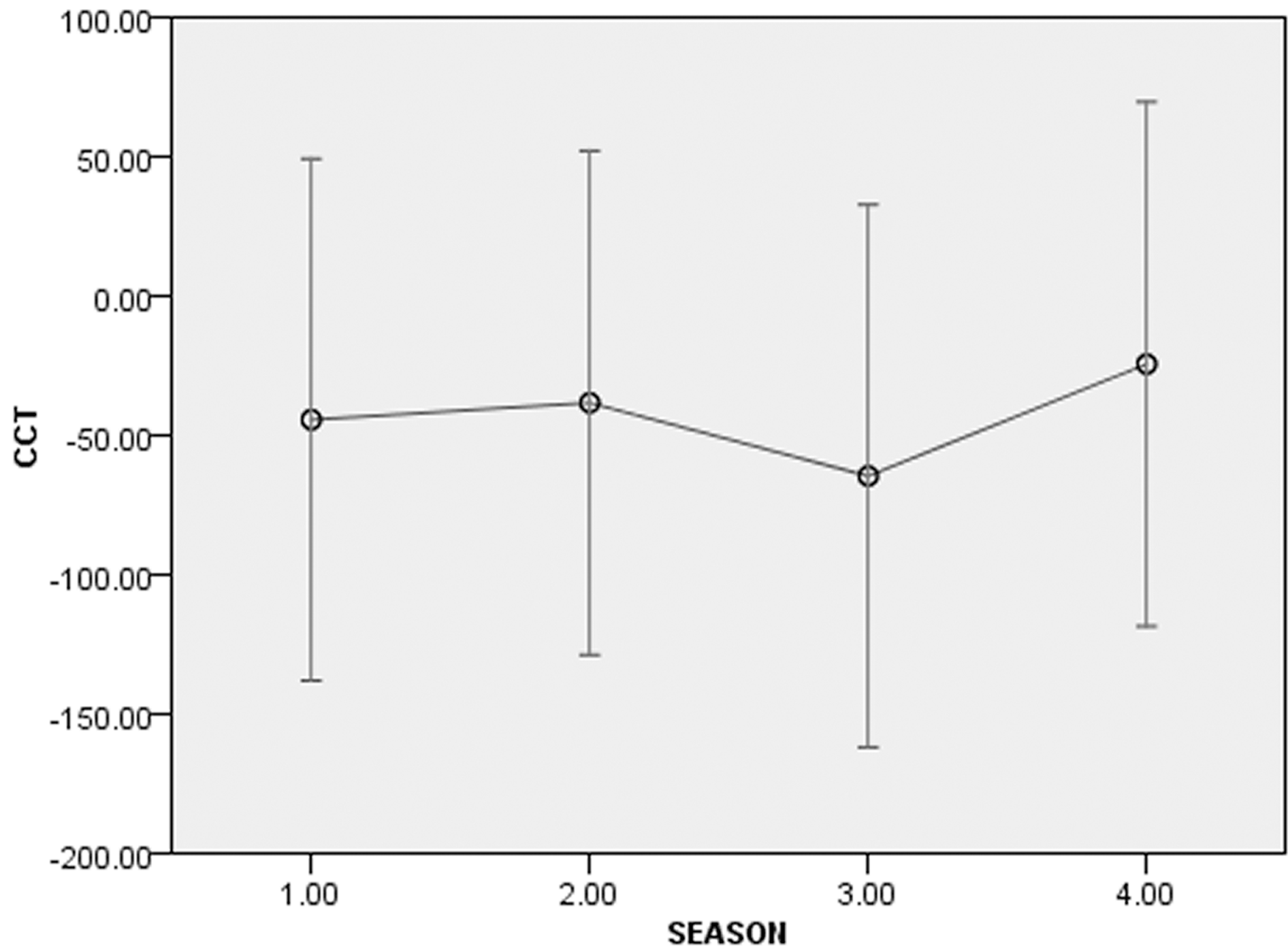

Fig 4. SPSS 20.0 output bar graph showing estimated means of Corrected Conciliatory Tendency (CCT, \%) for the significant effect (season: 1 = lactation; 2: pre-mating; $\mathbf{3}$ = mating; $\mathbf{4}$ = pregnancy), for all the study groups. Season is the only factor that significantly influences the CCT distribution in the study groups (GLMM; $F=0.718, \mathrm{df} 1=73, \mathrm{df} 2=40, p=0.890)$. The conciliatory tendency $\%$ is lowest during mating.

doi:10.1371/journal.pone.0142150.g004

during hunts, defence of ungulate carcasses against competitors, and coalition formation that is important in both the acquisition and maintenance of social rank [53]. Cooperation and despotism are two opposite forces that contribute in shaping reconciliation patterns, as it becomes especially clear when comparing species differing only in some aspects of the social system. In hyenas, as in wolves, the necessity to cooperate overcomes the competition between dominants and subordinates, which explains the presence of reconciliation. The lower levels of reconciliation observed in hyenas (mean conciliatory tendency: 11.3\% [53]) may be due to the fact that, contrary to wolves, spotted hyenas live in a fission fusion society allowing dispersal (other than reconciliation) as an exit strategy. The influence of the cooperation pressure over the suitability of engaging in reconciliation is even more evident when comparing spotted hyenas with ring-tailed lemurs. Although both species possess steep female dominance, they strongly differ in the level of cooperation. Unlike hyenas, cooperation in L. catta is limited to the coalitionary support provided to the dominant female by other females during targeted aggression toward 


\begin{tabular}{|c|c|c|c|c|c|c|}
\hline \multirow{2}{*}{ Source } & \multirow{2}{*}{ Coefficient } & \multirow{2}{*}{$\begin{array}{c}\text { Standard } \\
\text { Error }\end{array}$} & \multirow{2}{*}{$\mathrm{t}$} & \multirow{2}{*}{$\mathrm{p}$} & \multicolumn{2}{|c|}{ Confidence interval 95\% } \\
\hline & & & & & Minimum & Maximum \\
\hline Intercetta & 48.915 & 93.485 & 0.523 & .604 & -140.335 & 238.165 \\
\hline $\mathrm{RANK}^{\star}[\mathrm{SEX}=0]$ & -8.824 & 13.829 & -0.638 & .527 & -36.819 & 19.172 \\
\hline $\mathrm{RANK}^{\star}[\mathrm{SEX}=1]$ & 26.264 & 41.741 & 0.629 & .533 & -58.237 & 110.764 \\
\hline $\mathrm{RANK}^{\star}[\mathrm{AGE}=0]$ & -26.899 & 29.194 & -0.921 & .363 & -85.999 & 32.201 \\
\hline $\mathrm{RANK}^{\star}[\mathrm{AGE}=1]$ & $0^{a}$ & & & & & \\
\hline SEASON=1 & -19.960 & 10.491 & -1.903 & .065 & -41.199 & 1.278 \\
\hline SEASON=2 & -13.889 & 12.302 & -1.129 & .266 & -38.793 & 11.016 \\
\hline SEASON=3 & -40.152 & 11.952 & -3.360 & .002 & -64.347 & -15.958 \\
\hline SEASON=4 & $0^{a}$ & & & & & \\
\hline SUBJECTS=an & -102.413 & 43.856 & -2.335 & .025 & -191.195 & -13.631 \\
\hline SUBJECTS=ank & -20.528 & 44.935 & -0.457 & .650 & -111.494 & 70.439 \\
\hline SUBJECTS=bk & -63.610 & 29.968 & -2.123 & .040 & -124.277 & -2.943 \\
\hline SUBJECTS $=$ co & 22.907 & 29.355 & 0.780 & .440 & -36.519 & 82.333 \\
\hline SUBJECTS=fi & 11.236 & 44.939 & 0.250 & .804 & -79.739 & 102.211 \\
\hline SUBJECTS=ma & -232.737 & 245.842 & -0.947 & .350 & -730.418 & 264.943 \\
\hline SUBJECTS=me & 31.698 & 35.347 & 0.897 & .375 & -39.858 & 103.254 \\
\hline SUBJECTS $=\mathbf{m i}$ & -61.290 & 43.469 & -1.410 & .167 & -149.289 & 26.709 \\
\hline SUBJECTS $=\mathbf{m r}$ & 39.605 & 45.030 & 0.880 & .385 & -51.552 & 130.763 \\
\hline SUBJECTS=ra & $0^{a}$ & & & & & \\
\hline
\end{tabular}

Fig 5. Output of the best model explaining the distribution of Corrected Conciliatory Tendencies (CCT \%, scalar target variable) for group $\mathrm{C}_{\mathrm{c}}$. AICc $=398.767$. Season: $1=$ lactation; $2=$ pre-mating; $3=$ mating; $4=$ pregnancy. Sex: $0=$ male; $1=$ female. Age class: $0=$ subadult; $1=$ adult. ${ }^{a}$ Redundant coefficients.

doi:10.1371/journal.pone.0142150.g005 


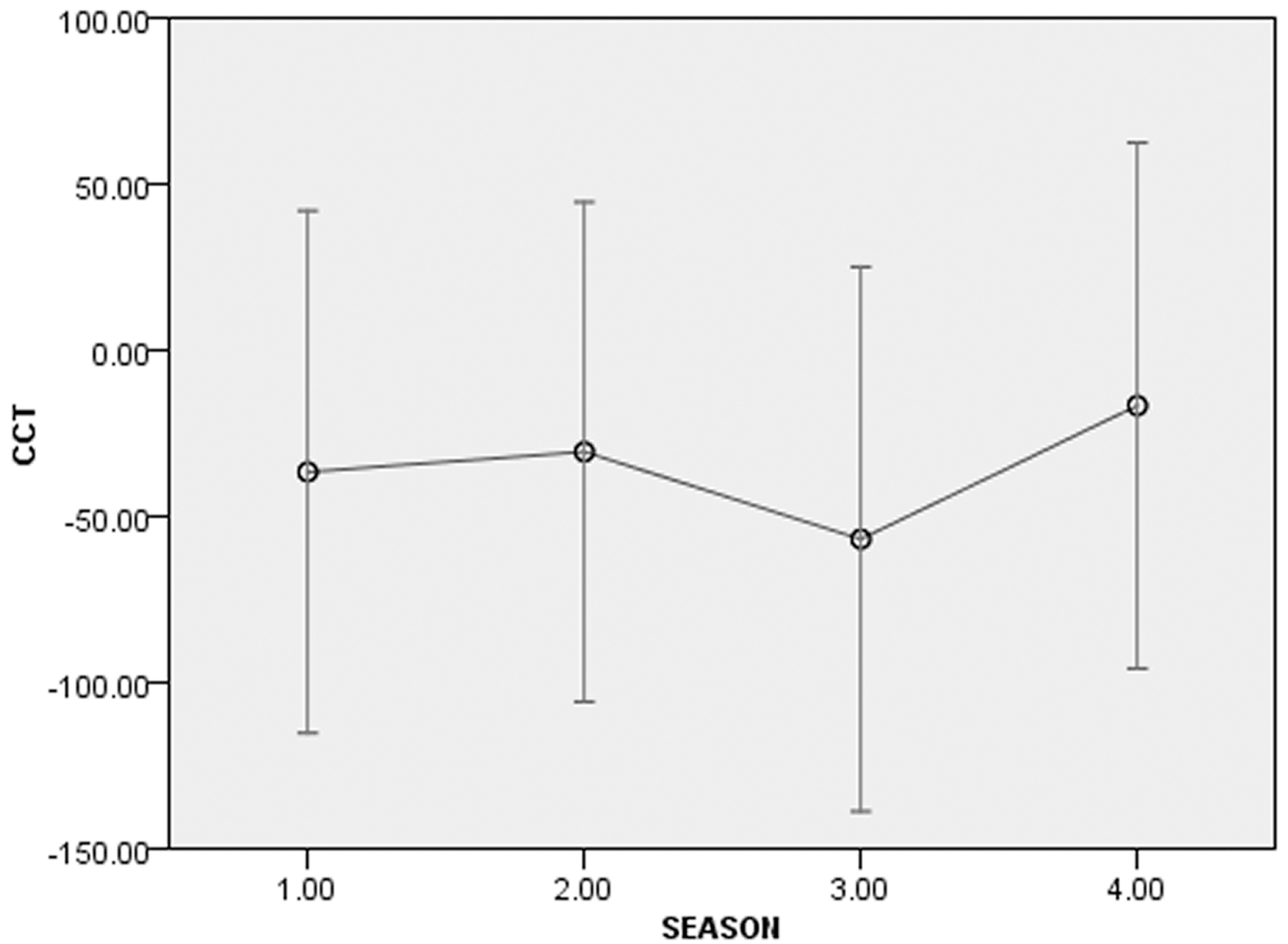

Fig 6. SPSS 20.0 output bar graph showing estimated means of Corrected Conciliatory Tendency (CCT, \%) for the significant effect (season: 1 = lactation; 2: pre-mating; $\mathbf{3}=$ mating; $\mathbf{4}$ = pregnancy), for group $\mathbf{C}_{\mathrm{c}}$. Season is the only factor that significantly influences the CCT distribution in the study groups (GLMM; $F=1.674$, df1 $=15, \mathrm{df} 2=36, \mathrm{p}=0.102)$. The conciliatory tendency $\%$ is lowest during mating.

doi:10.1371/journal.pone.0142150.g006

conspecifics (to defend territory boundaries or to evict them from the group or the core area of the home range; [10], [58], [121]). This limited cooperation can explain why L. catta show the lowest conciliatory tendencies (9-10\%). In some macaque species, it has been observed that the higher the cooperation and tolerance levels, the higher the reconciliation rates [52]. This principle can be extended to include other primates. For example, conciliatory tendencies can reach more than $40 \%$ in bonobos (Pan paniscus) and crested macaques (Macaca nigra) [22], [122] and plummet to less than $15 \%$ in more despotic and less cooperative species such as Assamese macaques (Macaca assamensis) and western gorillas (Gorilla beringei) [25], [123]. Of course, the distinction between more and less cooperative species is not always clear cut because primates can form rather complex societies and the individuals of certain subgroups can be more cooperative than the group as a whole, as occurs when cooperative breeding, matriline support, or brotherhood coalitions are in place [124]. 
Although at low levels, reconciliation seems to be possible in despotic species like L. catta when the cooperation-competition balance tilts in favor of cooperation because the benefits of peace making overcome the costs of leaving conflicts unmanaged. But when reproduction is at stake, as it is in lemurs during the once-a-year mating period, both male-female and male-male competition is too high [58],[125] for conflicts to be peacefully resolved. In our study we found that aggression in the mating period was particularly high between males and between females and males (with females initiating the aggression). Consistently, conciliatory rates of both males and females were minimal in the mating season (Figs 4 and 6) likely because in this period the behaviors of individuals are oriented toward reproduction more than maintenance of social stability. Based on these results, it is possible to assert that reconciliation is seasondependent in L. catta. Sex was not the explaining variable for the observed fluctuations in conciliatory tendencies. Consistently, both males and females initiated the post-conflict reunion with comparable frequencies throughout the year.

The only study to date that has investigated the seasonal fluctuations of reconciliation in another despotic primate species [84] reported that in female Japanese macaques (Macaca fuscata) mating — and not other factors such as changes in activity budgets and dietary composition - had profound effects on peace-making. In fact, the conciliatory tendency-informing reconciliation rates-was significantly lower during the mating season than the non mating season [84]. The authors commented that the negative effects of the mating season on reconciliation within female Japanese macaques may be due to the relevance of female competition for access to male partners in multimale, multifemale societies characterized by adult male dominance. In L. catta the situation is reversed: adult females are dominant over males [57-59] and the competition and stress levels during the mating period are highest among males trying to gain access to female partners [125]. Despite the difference in the dominant sex between L. catta and M. fuscata, the result is similar: reconciliation is lowest during the extremely competitive mating period.

A possible explanation for the seasonal distribution of reconciliation can lie in how hormones modulate the propensity to affiliate with others, and consequently to reconcile. It is worth remembering that the very definition of reconciliation implies the use of affinitive contacts for the purpose of peace making [20]. As well as in other animals in which the sexual context is associated with aggression and competition [126], [127], L. catta males experience the highest levels of testosterone during the extremely high competitive mating period [128], which also coincides with the lowest levels of inter-male affiliation [91]. The stress hormones may also increase as a result of aggression, eliciting the fight or flight response [129] and therefore leaving little space for post-conflict affiliation among males. However, literature reports contrasting results on the level of stress hormones (fecal glucocorticoid) in L. catta males during the mating period [125].

Besides male affiliation, the high levels of estradiol associated with the mating period can reduce affiliation between primate females, for example in rhesus monkeys (Macaca mulatta [130]). Additionally, in human and non human primates, other hormones such as oxytocin and prolactin may influence female affiliation levels throughout the year because they can enhance individual propensity to affiliate and are higher in non-mating periods [131-138]. Consistently, L. catta females (aggressors) mainly initiated conciliatory affiliation in group $\mathrm{A}_{c}$ [65]. Therefore, hormonal influence may partly explain the variation in post-conflict conciliatory affiliation across the year.

The seasonality of the conciliatory tendency in L. catta documented in the present study is also consistent with the variation of inter-male affiliation rates recorded by Gabriel, Gould \& Kelley [91] in the same species, at four sites of Madagascar. These authors observed that intermale affiliation levels varied across reproductive periods, with the lowest frequencies occurring 
during the mating period. Overall, the seasonal fluctuations of the reconciliation tendency observed in L. catta appear to be sustained by both physiological and socio-ecological data.

Access to females is not the only item worth competing for. Another valuable resource connected to reproductive success is offspring. We observed that in both the wild and captivity female-female aggression was highest during pregnancy and during the lactation period (Table 3), when the newborn is still carried out by the mother. It has been hypothesised that dominant females may target subordinate ones to prevent them from conceiving or to cause them to lose their infants because subordinate females with vital offspring can potentially acquire a higher ranking status in the social group and subtract resources [58], [121]. Food also represents a valuable commodity for the members of social groups, eliciting competition more than cooperation. Consistently, in the wild, reconciliation was found in a group of Eulemur rufus $x$ collaris and in two groups of Propithecus verreauxi but never in the feeding context [45], [73]. This situation reinforces the idea that when a valuable resource is concerned and cooperation is low (e.g. mate for reproduction, high energy food), gaining access to that resource can be more rewarding than repairing the relationship with a former opponent in the short term, via post-conflict reunions. As a future direction, it would be interesting to assess if and how conciliatory tendencies of $L$. catta are influenced by the context and the individuals involved in the conflicts within each season. We expect that post conflict reunions are lowest in competive contexts (e.g. feeding) and between competing individuals (e.g. females during pregnancy and lactation; males during mating, etc.).

In conclusion, we posit that the ability to reconcile is expressed whenever the benefits of intra-group cooperation overcome the costs of competition, as occurs when a limited, wanted resource is at stake. In summary, this study shows that in despotic social groups in which coalitions are observed, the right question is not if but when reconciliation can be present.

\section{Supporting Information}

S1 Dataset. Dataset used to investigate the occurrence and seasonality reconciliation in Lemur catta.

(XLSX)

S1 Fig. Full size version of Fig 3.

\section{Acknowledgments}

The authors thank the De Heaulme family and Alison Jolly for the possibility of doing this research at Berenty (Madagascar). They express gratitude to the Director of the Giardino Zoologico di Pistoia (Pistoia, Italy), Paolo Cavicchio and the lemur keepers for allowing and facilitating the work in captivity. The authors wish to thank also Elena Bastianelli, Elisa Rigosi, Manrica Cresci, Daniela Antonacci, Stefano Kaburu, Chandra Brondi, Stefania Dall'Olio, Valentina Sclafani, Viola Caltabiano, Giulia Spada, Alessandra Zannella for helping with data collection over the years, Stacey Schmidt Zander for language revision, and Beronia Rioja for enhancing the discussion over results. Finally the authors are grateful to the parks Giardino Zoologico di Pistoia, Parco Zoo Falconara (Falconara, Italy), and Parco Zoo Punta Verde (Lignano Sabbiadoro, Italy) for supporing the field data collection in the wild.

\section{Author Contributions}

Conceived and designed the experiments: EP IN. Performed the experiments: EP IN. Analyzed the data: EP IN. Contributed reagents/materials/analysis tools: EP IN. Wrote the paper: EP IN. 


\section{References}

1. Galtung J (1969) Violence, peace, and peace research. J Peace Research 6: 167-191.

2. Bygott J, Bertram B, Hanby J (1979) Male lions in large coalitions gain reproductive advantages. Nature 282: 839-841.

3. Clutton-Brock T (1998) Reproductive skew, concessions and limited control. Trends Ecol Evol 13: 288-292. PMID: 21238306

4. Duffy KG, Wrangham RW, Silk JB (2007) Male chimpanzees exchange political support for mating opportunities. Curr Biol 17: R586-R587. PMID: 17686425

5. Cordoni G, Palagi E (2008). Reconciliation in wolves (Canis lupus): new evidence for a comparative perspective. Ethology 114: 298-308.

6. Dovidio JF, Saguy T, Shnabel N (2009) Cooperation and conflict within groups: intragroup and intergroup processes. J Soc Issues 65: 429-449.

7. Snyder-Mackler N, Alberts SC \& Bergman TJ (2012) Concessions of an alpha male? Cooperative defence and shared reproduction in multi-male primate groups. Proc Bio Sci 279: 3788-3795.

8. Boesch C (1994) Cooperative hunting in free chimpanzees. Anim Behav 48: 653-667.

9. Smith AS, Ågmo A, Birnie AK, French JA (2010) Manipulation of the oxytocin system alters social behavior and attraction in pair-bonding primates, Callithrix penicillata. Horm Behav 57: 255-262. doi: 10.1016/j.yhbeh.2009.12.004 PMID: 20025881

10. Soma T \& Koyama N (2013) Eviction and troop reconstruction in a single matriline of ring-tailed lemurs (Lemur catta): what happened when "grandmother" died? In: Masters J, Gamba M, Génin F, eds. Leaping ahead-Advances in prosimian biology. New York: Springer. pp 137-146.

11. Baan $C$, Bergmüllera R, Smithb DW, Molnara B (2014) Conflict management in free-ranging wolves, Canis lupus. Anim Behav 90: 327-334.

12. de Waal FBM (2004) Evolutionary ethics, aggression, and violence: lessons from primate research. J Law Med Ethics 32: 18-23. PMID: 15152422

13. Fraser ON, Bugnyar $T$ (2011) Ravens reconcile after aggressive conflicts with valuable partners. PLoS ONE 6(3): e18118. doi: 10.1371/journal.pone.0018118 PMID: 21464962

14. Schino $G$ (1998) Reconciliation in domestic goats. Behaviour 135: 343-356.

15. Weaver A (2003) Conflict and reconciliation in captive bottlenose dolphins, Tursiops truncatus. Mar Mam Sci 19: 836-846.

16. Cools AKA, van Hout AJM, Nelissen MHJ (2008) Canine reconciliation and third-party-initiated postconflict affiliation: do peacemaking social mechanisms in dogs rival those of higher primates? Ethology 113: 53-63.

17. Cozzi A, Sighieri C, Gazzano A, Nicol CJ,Baragli $P$ (2010) Post-conflict friendly reunion in a permanent group of horses (Equus caballus). Behav Proc 85: 185-190.

18. Cordoni G, Norscia I (2014) Peace-Making in marsupials: the first study in the red-necked wallaby (Macropus rufogriseus). PLoS ONE 9(1): e86859. doi: 10.1371/journal.pone.0086859 PMID: 24489796

19. Fujisawa KK, Kutsukake N, Hasegawa T (2005) Reconciliation pattern after aggression among Japanese preschool children. Aggr Behav 31: 138-152.

20. de Waal FBM, van Roosmaleen A (1979) Reconciliation and consolation among chimpanzees. Behav Ecol Sociobiol 5: 55-66.

21. Arnold K, Whiten A (2001) Post-conflict behaviour of wild chimpanzees (Pan troglodytes schweinfurthii) in the Budongo forest, Uganda. Behaviour 138, 649-690.

22. Palagi E, Paoli T, Borgonini Tarli S (2004) Reconciliation and consolation in captive bonobos (Pan paniscus). Am J Primatol 62: 15-30. PMID: 14752810

23. Watts DP (1995a) Post-conflict social events in wild mountain gorillas (Mammalia, Hominoidea). I. Social interactions between opponents. Ethology 100: 139-157.

24. Watts DP (1995b) Post-conflict social events in wild mountain gorillas. II. Redirection, side direction, and consolation. Ethology 100: 158-174.

25. Cordoni G, Palagi E, Borgognini Tarli SM (2006) Reconciliation and consolation in captive western gorillas. Int J Primatol 27: 1365-1382.

26. Aureli $F$ (1992) Post-conflict behaviour among wild long-tailed macaques (Macaca fascicularis). Behav Ecol Sociobiol 31: 329-337

27. Cooper MA, Aureli F, Singh M (2007) Sex differences in reconciliation and postconflict anxiety in bonnet macaques. Ethology 113: 26-38 
28. Björnsdotter M, Larsson $L$, Ljungberg $T$ (2000) Postconflict affiliation in two captive groups of blackand-white guereza Colobus guereza. Ethology 196: 289-300

29. York AD, Rowell TE (1988) Reconciliation following aggression in patas monkeys, Erythrocebus patas. Anim Behav 36: 502-509.

30. Pereira ME, Schill JL, Charles EP (2000) Reconciliation in captive Guyanese squirrel monkeys (Saimiri sciureus). Am J Primatol 50: 159-167 PMID: 10676712

31. Leca JB, Fornasieri I, Petit O (2002) Aggression and reconciliation in Cebus capucinus. Int J Primatol 23: 979-998.

32. de Waal FBM (1986) The integration of dominance and social bonding in primates. Q Rev Biol 61: 459-479. PMID: 3543991

33. Cords M (1992) Post conflict reunions and reconciliation in longtailed macaques. Animal Behav 44: 57-61.

34. Kappeler PM, van Schaik CP (1992) Methodological and evolutionary aspects of reconciliation among primates. Ethology 92: 51-69.

35. Cords M, Thurnheer S (1993) Reconciliation with valuable partners by long-tailed macaques. Ethology 93: 315-325.

36. Aureli F, de Waal FBM (2000) Natural Conflict Resolution. Berkeley, California (USA): University of California Press.

37. Demaria C, Thierry B (2001) A comparative study of reconciliation in rhesus and Tonkean macaques. Behaviour 138: 397-410.

38. Wittig RM, Boesch C (2005) How to repair relationships: reconciliation in wild chimpanzees (Pan troglodytes). Ethology 111: 736-763.

39. Aureli F, Schaffner C (2006) Causes, consequences and mechanisms of reconciliation: the role of cooperation. In: van Schaik CP, Kappeler PM, eds. Cooperation in Primates and Humans. Mechanisms and Evolution. Heidelberg: Springer. pp 121-136.

40. Aureli F, van Schaik CP, van Hooff JARAM (1989) Functional aspects of reconciliation among captive long-tailed macaques (Macaca fascicularis). Am J Primatol 19: 38-51.

41. Aureli F, van Schaik CP (1991) Post-conflict behaviour in longtailed macaques (Macaca fascicularis): II. Coping with the uncertainty. Ethology 89: 101-114

42. Koyama $\mathrm{N}$ (2001) The long-term effects of reconciliation in Japanese macaques Macaca fuscata. Ethology 107: 975-987.

43. Kutsukake N, Castles DL (2001) Reconciliation and variation in post-conflict stress in Japanese macaques (Macaca fuscata fuscata): testing the integrated hypothesis. Anim Cogn 4:259-268. doi: 10.1007/s10071-001-0119-2 PMID: 24777516

44. Palagi E, Chiarugi E, Cordoni G (2008) Peaceful post-conflict interactions between aggressors and bystanders in captive lowland gorillas (Gorilla gorilla gorilla). Am J Primatol 70: 949-955 doi: 10.1002/ ajp.20587 PMID: 18615459

45. Norscia I, Palagi E (2011) Do brown lemurs reconcile? Not always. J Ethol 29: 181-185

46. Castles DL, Whiten A (1998) Post-conflict behaviour of wild olive baboons. I. Reconciliation, redirection and consolation. Ethology 104: 126-147

47. Das M, Penke Z, van Hooff JARAM (1998) Post-conflict affiliation and stress-related behavior of longtailed macaque aggressors. Int J Primatol 19: 53-71.

48. Aureli F, Smucny D (2000) The role of emotion in conflict and conflict resolution. In: Aureli F, de Waal FBM, eds. Natural Conflict Resolution. Berkeley, California: University of California Press. pp 199224.

49. Butovskaya ML Boyko EY Selverova NB, Ermakova IV (2005) The hormonal basis of reconciliation in humans. J Physiol Anthropol App Hum Sci 24: 333-337.

50. Palagi E \& Norscia I (2011) Scratching around stress: hierarchy and reconciliation make the difference in wild brown lemurs (Eulemur fulvus). Stress 14: 93-97. doi: 10.3109/10253890.2010.505272 PMID: 20666657

51. Aureli $F$, Cords $M$, Van Schaik C P (2002) Conflict resolution following aggression in gregarious animals: a predictive framework. Anim Behav 64: 325-343

52. Flack J, de Waal FBM (2004) Dominance style, social power, and conflict. In: Thierry B, Singh M, Kaumanns W, eds. Macaque societies: a model for the study of social organization. Cambridge: Cambridge University Press. pp. 157-185

53. Wahaj SA Guse KR, Holekamp KE 2001 Reconciliation in spotted hyena (Crocuta crocuta). Ethology 107: 1057-1074. 
54. Chaffin CL, Friedlen K, de Waal FBM (1995) Dominance style of Japanese macaques compared with rhesus and stumptail macaques. Am J Primatol 35:103-116.

55. Cheney DL, Seyfarth RM, Silk JB (1995) The role of grunts in reconciling opponents and facilitating interactions among adult female baboons. Anim Behav 50: 249-257.

56. Norscia I \& Palagi E (2015) The socio-matrix reloaded: from hierarchy to dominance profile in wild lemurs. PeerJ 3: e729. doi: 10.7717/peerj.729 PMID: 25653908

57. Sclafani $V$, Norscia I, Antonacci D, Palagi E (2012) Scratching around mating: factors affecting anxiety in wild Lemur catta. Primates 53: 247-254. doi: 10.1007/s10329-012-0294-6 PMID: 22278710

58. Jolly A (1966) Lemur behavior: a Madagascar field study. Chicago (USA): University of Chicago Press.

59. Sauther ML, Sussman RW, Gould L (1999) The socioecology of the ringtailed lemur: thirty-five years of research. Evol Anthropol 8: 120-132.

60. Nakamichi M \& Koyama N (1997). Social relationships among ring-tailed lemurs (Lemur catta) in two free-ranging troops at Berenty Reserve, Madagascar. Int J Primatol 18:73-93.

61. Jolly A (1984) The puzzle of female feeding priority. In: Small M, ed. Female primates: studies by women primatologists. New York: Alan R. Liss. pp 197-215.

62. Kappeler PM (1990) Female dominance in Lemur catta: More than just female feeding priority? Folia Primatol 55: 92-95. PMID: 2227726

63. Taylor L, Sussman RW (1985) A preliminary study of kinship and social organization in a semifreeranging group of Lemur catta. Int J Primatol 6: 601-614.

64. Kappeler PM (1993) Reconciliation and post-conflict behaviour in ringtailed lemurs, Lemur catta, and redfronted lemurs, Eulemur fulvus rufus. Anim Behav 45: 901-915.

65. Palagi E, Paoli T \& Borgognini Tarli SM (2005) Aggression and reconciliation in two captive groups of Lemur catta. Int J Primatol 26: 279-294.

66. Fry DP (2012) Life without war. Science 336: 880-884

67. Sueur C, Petit O, De Marco A, Jacobs AT, Watanabe K, Thierry B (2011) A comparative network analysis of social style in macaques. Anim Behav 82: 845-852

68. Palagi E, Dall'Olio S, Demuru E, Stanyon R (2014) Exploring the evolutionary foundations of empathy: consolation in monkeys. Evol Hum Behav 35: 341-349.

69. Petit O, Thierry B (1994) Aggressive and peaceful interventions in conflicts in Tonkean macaques. Anim Behav 48: 1427-1436.

70. Thierry B (1985a) Patterns of agonistic interactions in three species of macaque (Macaca mulatta, $M$. fascicularis, M. tonkeana). Aggr Behav 11: 223-233.

71. Thierry B (1985b) Social development in three species of macaque (Macaca mulatta, M. fascicularis, M. tonkeana): a preliminary report on the first ten weeks of life. Behav Proc 11: 89-95.

72. Roeder JJ, Fornasieri I \& Gosset D (2002) Conflict and postconflict behaviour in two lemur species with different social organizations (Eulemur fulvus and Eulemur macaco): a study on captive groups. Agg Behav 28: 62-74

73. Palagi E, Antonacci D \& Norscia I (2008) Peacemaking on treetops: first evidence of reconciliation from a wild prosimian (Propithecus verreauxi). Anim Behav 76: 737-747.

74. Fleagle JG (2013). Primate adaptation and evolution. Third Edition. San Diego (USA): Academic Press.

75. Frank LG (1986) Social organization of the spotted hyaena Crocuta crocuta. II. Dominance and reproduction. Anim Behav 34: 1510-1527.

76. Fentress JC, Ryon J, McLeod PJ, Havkin GZ (1987) A multidimensional approach to agonistic behavior in wolves. In: Frank $\mathrm{H}$, ed. Man and wolf: advances, issues and problems in captive wolf research. Boston (MA, USA): Dr. W. Junk Publishers. pp 253-274.

77. Sussman RW, Richard AF (1974) The role of aggression among diurnal prosimians. In: Holloway RL, ed. Primate aggression, territoriality, and xenophobia. San Francisco (USA): Academic. pp 50-76.

78. Palagi E, Telara S \& Borgognini Tarli SM (2003) Sniffing behavior in Lemur catta: seasonality, sex, and rank. Int J Primatol 24: 335-350.

79. Palagi E, Telara S \& Borgognini Tarli SM (2004) Reproductive strategies in Lemur catta: balance among sending, receiving, and counter-marking scent signals. Int J Primatol 25: 1019-1031.

80. Messier $F$ (1985) Social organization, spatial distribution, and population density of wolves in relation to social status and prey abundance. Can J Zool 63: 1068-1077. 
81. Henschel JR, Skinner JD (1991) Territorial behaviour by a clan of spotted hyaenas Crocuta crocuta. Ethology 88: 223-235.

82. Holekamp KE, Smith JE, Strelioff CC, Van Horn RC, Watts HE (2012) Society, demography and genetic structure in the spotted hyena. Mol Ecol 21: 613-632. doi: 10.1111/j.1365-294X.2011.05240. x PMID: 21880088

83. Clutton-Brock TH, Huchard E (2013) Social competition and selection in males and females. Philos Trans R Soc Lond B 368: 20130074.

84. Majolo B, Koiama N (2006) Seasonal Effects on Reconciliation in Macaca fuscata yakui. Int J Primatol 27: 1383-1397.

85. Jolly A (2003). Lemur catta, ring-tailed lemur, Maky. In: Goodman SM, Benstead JP, eds. The Natural History of Madagascar. The University of Chicago Press: Chicago, MA. pp. 1329-1331.

86. Wright PC (1999) Lemur Traits and Madagascar Ecology: Coping With an Island Environment. Yearb Phys Anthropol 42: 31-72

87. Evans CS, Goy RW (1968) Social behaviour and reproductive cycles in captive ring-tailed lemurs (Lemur catta). J Zool Lond 156: 181-197.

88. Koyama N (1988) Mating behavior of ringtailed lemurs (Lemur catta) at Berenty, Madagascar. Primates 29: 163-175

89. Cavigelli SA, Pereira ME (2000) Mating season aggression and fecal testosterone levels in male ringtailed lemurs (Lemur catta). Horm Behav 37:246-255. PMID: 10868488

90. Koyama N (1988) Mating behavior of ring-tailed lemurs (Lemur catta) at Berenty, Madagascar. Primates 29: 163-175

91. Gabriel DN, Gould L, Kelley EA (2014) Seasonal patterns of male affiliation in ring-tailed lemurs (Lemur catta) in diverse habitats across southern Madagascar. Behaviour 151: 935-961.

92. Sauther ML (1991) Reproductive behavior of free-ranging Lemur catta at Beza Mahafaly Special Reserve, Madagascar. Am J Physical Anthropol 84: 463-77.

93. Gould $L$ (1999) How female dominance and reproductive seasonality affect the social lives of adult male ringtailed lemurs (Lemur catta) In: Dolinhow PJ, Fuentes A, eds. The Non-Human Primates. Mayfield Press: MountainView CA. pp 133-139.

94. Palagi E, Norscia I (2009) Multimodal signaling in wild Lemur catta: economic design and territorial function of urine marking. Am J Phy Anthropol 139:182-192.

95. Gould L, Kelley EA, LaFleur M. 2015. Reproductive female feeding strategies in spiny forest-dwelling Lemur catta in southern and southwestern Madagascar: how do females meet the challenges of reproduction in this harsh habitat? Fol primatol 86: 16-24.

96. LaFleur M, Sauther M, Cuozzo F, Yamashita N, Youssouf IAJ, Bender R (2014) Cathemerality in wild ring-tailed lemurs (Lemur catta) in the spiny forest of Tsimanampetsotsa National Park: camera trap data and preliminary behavioral observations. Primates 55: 207-217.

97. Donati G, Santini L, Razafindramanana J, Boitani L, Borgognini-Tarli S. (2013) (Un-)expected nocturnal activity in "diurnal" Lemur catta supports cathemerality as one of the key adaptations of the lemurid radiation. Am J Phys Anthropol 150: 99-106. doi: 10.1002/ajpa.22180 PMID: 23180596

98. Kappeler PM (1990) Social-status and scent-marking behavior in Lemur catta. Anim Behav 40: 774776.

99. Koyama N, Ichino S, Nakamichi M, Takahata Y (2005) Long-term changes in dominance ranks among ring-tailed lemurs at Berenty Reserve, Madagascar. Primates 46: 225-234 PMID: 16142423

100. Gould $L$ (1997) Affiliative relationships between adult males and immature group members in naturally-occurring ringtailed lemurs (Lemur catta). Am J Phys Anthropol 103:167-171.

101. Budnitz N, Dainis K (1975) Lemur catta: ecology and behavior. In: Tattersall I, Sussman RW, eds. Lemur Biology. New York: Plenum. pp 219-235.

102. Gould L, Ziegler TE, Wittwer DJ (2005) Effects of reproductive and social variables on fecal glu-cocorticoid levels in a sample of adult male ring-tailed lemurs (Lemur catta) at the Beza Mahafaly Reserve, Madagascar. Am J Primatol 67: 5-23. PMID: 16163722

103. Jolly A (1967) Breeding synchrony in wild Lemur catta. In: Altmann SA, ed. Social communication in primates. Chicago (USA): University of Chicago Press. pp 1-14.

104. Pereira ME (1991) Asynchrony within estrous synchrony among ringtailed lemurs. Primates: Lemuridae. Physiol Behav 49: 47-52. PMID: 2017479

105. Jolly A, Koyama N, Rasamimanana H, Crowley H, Williams G (2006) Berenty Reserve: a research site in southern Madagascar. In: Jolly A, Sussman RW, Koyama N, Rasamimanana H, eds. Ringtailed lemur biology: Lemur catta in Madagascar. New York: Springer-Verlag. pp 32-42. 
106. Ichino S (2006) Troop fission in wild ring-tailed lemurs (Lemur catta) at Berenty, Madagascar. Am J Primatol 68: 97-102. PMID: 16419123

107. Jolly A (2012) Berenty Reserve, Madagascar: a long time in a small space. In: Kappeler PM, Watts DP, eds. Long-term field studies of primates. Berlin Heidelberg: Springer-Verlag. pp. 22-44.

108. Martin P, Bateson P (2007) Measuring behaviour: an introductory guide. Third edition. Cambridge (UK): Cambridge University Press.

109. Pereira ME, Kappeler PM (1997) Divergent systems of agonistic behaviour in lemurid primates. Behaviour 134: 225-274.

110. de Waal FBM, Yoshihara D (1983) Reconciliation and redirected affection in rhesus monkeys. Behaviour 85, 224-241.

111. Kappeler PM, van Schaik CP (2002) Evolution of primate social systems. Int J Primatol 23: 707-740.

112. Mundry R, Fischer J (1998) Use of statistical programs for nonparametric tests of small samples often leads to incorrect $P$ values: examples from animal behaviour. Anim Behav 56: 256-259 PMID: 9710485

113. Siegel S, Castellan NJ (1988) Nonparametric statistics for the behavioral sciences. New York (USA): McGraw Hill.

114. Veenema H, Das M, Aureli F (1994) Methodological improvements for the study of reconciliation. Behav Proc 31: 29-38.

115. Jaeggi AV, Stevens JMG, van Schaik CP (2010) Tolerant food sharing and reciprocity is precluded by despotism among bonobos but not chimpanzees. Am J Phys Anthropol 143: 41-51. doi: 10.1002/ ajpa.21288 PMID: 20310060

116. de Vries $\mathrm{H}$ (1993) The rowwise correlation between two proximity matrices and the partial rowwise correlation. Psychometrika 58: 53-69.

117. Palagi E, Gregorace A, Borgognini-Tarli S (2002) Development of olfactory behavior in captive ringtailed lemurs (Lemur catta). Int J Primatol 23: 587-599.

118. Mech LD (1977) Productivity, mortality and population trend of wolves in northeastern Minnesota. J Mammal 58: 559-574.

119. Zimen E (1981) The Wolf: A Species in Danger. New York (USA): Delatorre Press.

120. Mech LD, Boitani L (2003) Wolf social ecology. In: Mech LD \& Boitani L, eds. Behavior, Ecology, and Conservation. Chicago (USA): The University of Chicago Press. pp 1-34.

121. Vick LG, Pereira ME (1989) Episodic targeting aggression and the histories of lemur social groups. Behav Ecol Sociobiol 25: 3-12.

122. Duboscq J, Micheletta J, Agil M, Hodges K, Thierry B, Engelhardt A. (2013). Social tolerance in wild female crested macaques (Macaca nigra) in Tangkoko-Batuangus Nature Reserve, Sulawesi, Indonesia. Am J Primatol 75: 361-375. doi: 10.1002/ajp.22114 PMID: 23307343

123. Cooper MA, Bernstein IS (2002) Counter aggression and reconciliation in Assamese macaques (Macaca assamensis). Am J Primatol 56: 215-230. PMID: 11948638

124. Silk JB (2009) Nepotistic cooperation in non-human primate groups. Philos Trans R Soc Lond B Biol Sci 364: 3243-3254. doi: 10.1098/rstb.2009.0118 PMID: 19805431

125. Starling AP, Charpentier MJE, Fitzpatrick C, Scordato ES, Drea CM (2010) Seasonality, sociality, and reproduction: Long-term stressors of ring-tailed lemurs (Lemur catta). Horm Behav 57: 76-85. doi: 10.1016/j.yhbeh.2009.09.016 PMID: 19804779

126. Goldey KM, van Anders SM (2014) Sexual modulation of testosterone: insights for humans from across species. Adapt Hum Behav Physiol.

127. Barrett GM, Shimizu K, Bardi M, Asaba Shinsuke, Mori A (2002) Endocrine correlates of rank, reproduction, and female-directed aggression in male Japanese macaques (Macaca fuscata). Horm Behavior 42: 85-96.

128. Gould L, Ziegler TE 2007. Variation in fecal testosterone levels, inter-male aggression, dominance rank and age during mating and post-mating periods in wild adult male ring-tailed lemurs (Lemur catta). Am J Primatol 69: 1325-1339. PMID: 17427976

129. Sapolsky RM (1990) Stress in the wild. Sci Am 262: 116-123. PMID: 2294581

130. Wallen K, Tannenbaum PL (1997) Hormonal modulation of sexual behavior and affiliation in rhesus monkeys. Ann N Y Acad Sci 807: 185-202. PMID: 9071351

131. Campbell A (2008) Attachment, aggression and affiliation: The role of oxytocin in female social behavior. Biol Psychol 77: 1-10. PMID: 17931766

132. Feldman $R$ (2012) Oxytocin and social affiliation in humans. Horm Behav 61: 380-391. doi: 10.1016/ j.yhbeh.2012.01.008 PMID: 22285934 
133. Drago F, Pedersen CA, Caldwell JD, Prange AJ Jr (1986) Oxytocin potently enhances noveltyinduced grooming behavior in the rat. Brain Res 368: 287-295. PMID: 3697728

134. Smith JE, Van Horn RC, Powning KS, Cole AR, Graham KE, Memenis SK, Holekamp KE (2010) Evolutionary forces favoring intragroup coalitions among spotted hyenas and other animals. Behav Ecol 21: 284-303.

135. Turner RA, Altemus M, Enos T, Cooper B \& McGuinness T (1999) Preliminary research on plasma oxytocin in normal cycling women: investigating emotion and interpersonal distress. Psychiatry 62 : 97-113. PMID: 10420425

136. Zak PJ (2005) Trust: a temporary human attachment facilitated by oxytocin. Behav Brain Sci 28 : 368-369.

137. Botchin MB, Kaplan JR, Manuck SB, Mann JJ (1993) Low versus high prolactin responders to fenfluramine challenge: marker of behavioral differences in adult male cynomolgus macaques. Neuropsychopharmacology 9: 93-99. PMID: 8216698

138. Gettler LT, McDade TW, Feranil AB, Kuzawa CW (2009) Prolactin, fatherhood, and reproductive behavior in human males. Am J Phys Anthropol 148: 362-370. 